\title{
RELAÇÕES SOLO-VEGETAÇÃO EM ÁREAS SOB PROCESSO DE DESERTIFICAÇÃO NO MUNICÍPIO DE JATAÚBA, PE ${ }^{(1)}$
}

\author{
Izabel Cristina de Luna Galindo ${ }^{(2)}$, Mateus Rosas Ribeiro ${ }^{(3)}$, Maria \\ de Fátima de Araújo Vieira Santos ${ }^{(4)}$, José Fernando Wanderley \\ Fernandes Lima $^{(5)} \&$ Rafael Fernandes de Abreu e Lima Ferreira ${ }^{(6)}$
}

\begin{abstract}
RESUMO
A degradação das terras na região semi-árida resulta de processos naturais, que podem ser induzidos ou catalisados pelo homem por meio do uso inadequado dos recursos naturais, produzindo a deterioração da cobertura vegetal, do solo e dos recursos hídricos. Visando relacionar os processos de degradação da vegetação e dos solos na zona do agreste de Pernambuco, foram caracterizados os solos e o recobrimento vegetal em doze parcelas representativas de ambientes conservados, moderadamente degradados e degradados, no município de Jataúba. Para caracterizar a vegetação, os indivíduos foram classificados em três estratos verticais ou classes de altura: 3 - indivíduos com altura superior a $3,0 \mathrm{~m}$ (lenhosas altas), amostrados em toda a área da parcela $\left(200 \mathrm{~m}^{2}\right) ; 2$ - indivíduos com altura variando de 0,51 a 3,0 m, amostrados em subárea de $100 \mathrm{~m}^{2}$ (lenhosas baixas); 1 -indivíduos com altura igual ou inferior a $0,5 \mathrm{~m}$, amostrados em 18 miniparcelas de $25 \times 50 \mathrm{~cm}$ (estrato da regeneração). Os solos de cada parcela foram caracterizados morfologicamente e as amostras coletadas por horizonte para realização das análises físicas, químicas e mineralógicas. A vegetação no segundo estrato vertical apresentou significativa diminuição da densidade absoluta de acordo com a intensidade de degradação dos solos. As espécies com maiores densidades relativas foram: Neoglaziovia variegata (caroá) e Cordia leucocephala (moleque duro), no ambiente conservado; Bromelia laciniosa (macambira), Aspidosperma pyryfolium (pereiro) e Caesalpinia pyramidalis (catingueira), no ambiente moderadamente degradado, e C. pyramidalis e Sida galheirensis (malva branca), no ambiente
\end{abstract}

\footnotetext{
(1) Parte da Tese de Doutorado do primeiro autor, apresentada ao Programa de Pós-Graduação em Ciência do Solo da Universidade Federal Rural de Pernambuco - UFRPE. Trabalho financiado pelo CNPq. Recebido para publicação em junho de 2007 e aprovado em fevereiro de 2008.

${ }^{(2)}$ Professora Adjunta do Departamento de Agronomia da Universidade Federal Rural de Pernambuco - UFRPE. Av. D. Manuel de Medeiros s/n, Dois Irmãos, CEP 52171-900 Recife (PE). E-mail: iclgalindo@uol.com.br

(3) Professor Adjunto do Departamento de Agronomia, UFRPE. Bolsista do CNPq. E-mail: mateus.rosas@pq.cnpq.br

(4) Professora Adjunta do Departamento de Biologia, UFRPE. E-mail: fatimavs@hotlink.com.br

(5) Engenheiro-Agrônomo do Departamento de Agronomia, UFRPE. E-mail: zecasolos@yahoo.com.br

${ }^{(6)}$ Estudante de Agronomia, UFRPE. Bolsista do CNPq. E-mail: ralphael@terra.com.br
} 
degradado. As características dos Planossolos mais bem relacionadas com a vegetação preservada foram: os maiores conteúdos de cascalho nos horizontes superficiais, a maior espessura dos horizontes A + E e os teores mais elevados de CO. A ocorrência de encrostamento superficial e erosão e os elevados teores de Na trocável foram observados mais intensamente nos ambientes degradados, sendo mais severos onde a vegetação se encontrava mais esparsa.

Termos de indexação: semi-árido; degradação dos solos; erosão; indicadores de degradação.

\section{SUMMARY: SOILS AND VEGETATION RELATIONS IN AREAS UNDER DESERTIFICATION IN JATAÚBA COUNTY, PERNAMBUCO STATE, BRAZIL}

Land degradation in semiarid regions is a result of natural processes that can be induced or intensified by man through the inadequate use of natural resources, resulting in the degradation of vegetation, soil and water resources. Aiming to relate vegetation and soil degradation processes in the Agreste region of Pernambuco State, soil and vegetation in twelve representative plots were characterized as preserved, moderately degraded and degraded environments in the municipality of Jataúba. To study the vegetation, plants were stratified in three layers or height classes: 3 - plants taller than $3.0 \mathrm{~m}$, sampled in the total plot area $\left(200 \mathrm{~m}^{2}\right) ; 2$ - plants with a height between $0.51-3.0 \mathrm{~m}$, sampled in an area of $100 \mathrm{~m}^{2}$; 1 - plants with height equal to or less than $0.50 \mathrm{~m}$, sampled in 18 miniplots of $25 \times 50 \mathrm{~cm}$. Soils were morphologically characterized in each plot and samples collected from each horizon for physical, chemical and mineralogical analysis. The vegetation of the $2^{\text {nd }}$ stratum showed a great decrease in absolute density as a result of soil degradation intensity. Species with highest relative densities were: Neoglaziovia variegata (caroá) and Cordia leucocephala (moleque-duro) in the preserved area; Bromelia laciniosa (macambira), Aspidosperma pyrifolium (pereiro) and Caesalpinia pyramidalis (catingueira), in the moderately degraded area; and C. pyramidalis and Sida galheirensis (malva branca), in the degraded area. The soil properties of the Planosols that were strongly correlated with the preserved vegetation were the gravel contents in surface horizons, thickness of $A+E$ horizons, and the concentration of organic carbon. The occurrence of soil crusting and erosion, as well as high percentages of exchangeable sodium was observed with greater intensity at the degraded sites covered by more sparse vegetation.

Index terms: semiarid region; soil degradation; erosion; degradation indicators.

\section{INTRODUÇÃO}

A desertificação é o processo de degradação das terras nas zonas áridas, semi-áridas e subúmidas secas, resultante da ação de vários fatores, dentre os quais se destacam as variações climáticas e as atividades humanas (Brasil, 1999). Ocorre como um processo cumulativo de deterioração das condições ambientais que, em um estádio mais avançado, afeta as condições de vida da população (Saadi, 2000).

No Brasil, a grande maioria das terras susceptíveis à desertificação encontra-se nas regiões semi-áridas e subúmidas secas do Nordeste. O Plano Nacional de Combate à Desertificação (PNCD) estima que cerca de $181.000 \mathrm{~km}^{2}$ (20\% da área semi-árida do Nordeste) encontra-se em processo de desertificação (Brasil, 1998), problema que se vem agravando em decorrência das secas sucessivas que assolam o Nordeste e, principalmente, das pressões antrópicas em um ecossistema tipicamente frágil (Accioly, 2000).

Por ser um processo dinâmico, é difícil determinar uma causa para a desertificação das terras, tendo em vista que ela geralmente resulta de um emaranhado de causas e efeitos que se entrelaçam, formando um quadro complexo (Sampaio \& Sampaio, 2002). O uso e o manejo inadequado dos solos são apontados como as principais causas de origem antrópica relacionadas com a desertificação. No Nordeste semi-árido, várias formas de uso podem acarretar diferentes processos que resultam em degradação. O extrativismo vegetal e mineral, bem como o sobrepastoreio das pastagens nativas ou cultivadas, e o uso agrícola por culturas que expõem os solos aos agentes erosivos são as principais causas dos processos de desertificação que 
atingem a região. Quanto à intensidade, o fenômeno encontra-se concentrado em pontos específicos do bioma Caatinga, como um todo, resulta de um conjunto de procedimentos exploratórios ecologicamente incorretos e sua gravidade se expressa por meio da degradação conjunta de ativos ambientais, como solo, biodiversidade e recursos hídricos (CNRBC, 2004).

Quando se perde a cobertura arbustiva (por corte, queima ou pastoreio), a exposição do solo desnudo promove a formação de uma crosta superficial decorrente do impacto direto das gotas de chuva, o que reduz a infiltração da água e aumenta o escoamento. Isto diminui as possibilidades de estabelecimento da cobertura vegetal. Os solos descobertos são muito susceptíveis à erosão hídrica $\mathrm{e}$ eólica, causando uma remoção líquida de nutrientes das áreas degradadas (Gutiérrez \& Squeo, 2004). Nas áreas afetadas pela desertificação nas regiões semiáridas do Nordeste brasileiro, a vegetação apresentase com porte reduzido e maior espaçamento entre os seus componentes do que nas demais áreas, geralmente coincidindo com a presença da caatinga hiperxerófila aberta. Nesse tipo de caatinga e solo, a desertificação pode surgir espontaneamente, havendo, pois, a possibilidade de sua preexistência no Nordeste antes do aparecimento do colonizador (Vasconcelos Sobrinho, 1982). A característica fundamental do fenômeno da desertificação no semi-árido nordestino é a presença de manchas de solo exposto. São geralmente áreas de solos rasos, sem capacidade de retenção de água e com limitações físicas e químicas, que aumentam a vocação ecológica para a desertificação. O solo é o condicionante dessas áreas mais intensamente degradadas por entre caatingas mais altas e mais densas.

A degradação do solo pode ser definida como um processo que reduz a capacidade atual ou potencial do solo para produzir bens ou serviços. O solo é considerado degradado se os processos naturais e antropogênicos atuantes diminuíram a quantidade e qualidade da produção de biomassa, encarecendo os custos com a recuperação (Snakin et al., 1996). A degradação das condições do solo é um processo significativo, por dificilmente ser reversível, visto que os processos de formação além de regeneração ocorrem de forma predominantemente lenta (Sombroek \& Sene, 1993).

De acordo com Rodrigues (2000), não existe até hoje, no Brasil e no mundo, uma metodologia de consenso sobre qual a melhor forma de diagnosticar se uma área está ou não sofrendo processos de desertificação ou em qual grau ela se encontra. Esta dificuldade reside, basicamente, na escolha dos indicadores. Poucas são as variáveis que podem ser consideradas boas indicadoras, isto é, com representatividade, disponibilidade e confiabilidade espacial e temporal, além de facilidade de acesso. A caracterização da desertificação necessita de uma série temporal de dados. Uma análise atual da situação não pode dar a medida da variação no tempo. Qualquer análise com base neste quadro tem de trazer implícito um quadro de referência, em geral, uma suposição do que seria a situação passada. Segundo Sampaio \& Sampaio (2002), a ausência de séries temporais confiáveis é um dos problemas do estudo da desertificação no Nordeste, particularmente em relação a dados ambientais. $\mathrm{Na}$ ausência de dados de dinâmica, têm-se usado dados atuais para determinar a susceptibilidade à degradação, utilizando-se a baixa resiliência como medida da susceptibilidade.

Apesar do grande volume de trabalhos sobre monitoramento da qualidade do solo, envolvendo variados cenários ambientais e de manejo, poucos abordam a degradação dos solos em regiões secas. A ausência de padronização na metodologia da avaliação e nas etapas de amostragem, tratamento das amostras, análises e interpretação dos dados é um dos pontos críticos na abordagem do problema. O presente trabalho teve como objetivo caracterizar os solos e a vegetação em áreas de caatinga apresentando diferentes níveis de degradação, identificando quais atributos do solo refletem melhor o nível de degradação da vegetação, bem como fornecer subsídios para a elaboração de estratégias de recuperação.

\section{MATERIAL E MÉTODOS}

A área de estudo localiza-se no município de Jataúba, Mesorregião do Agreste Pernambucano ( $7^{\circ} 59^{\prime}$ Latitude Sul e $36^{\circ} 29^{\prime}$ Longitude Oeste), sendo caracterizada por clima do tipo BShs', segundo a classificação de Köppen, semi-árido de estepe de baixas latitudes, com chuvas de outono-inverno, e um período seco de sete a oito meses. A temperatura média anual é de $24^{\circ} \mathrm{C}$ e as precipitações pluviais são da ordem de $635 \mathrm{~mm}$, com período de chuvas concentrado de março a agosto, sendo os meses mais chuvosos março, abril e maio. A evapotranspiração potencial apresenta média anual de $1.000 \mathrm{~mm}$ (Jacomine et al., 1973). O índice de aridez (relação entre precipitação e evapotranspiração) é de 0,63. Situada numa área de semi-aridez acentuada, a região constitui uma projeção da zona fisiográfica do Cariri paraibano no Agreste de Pernambuco.

De acordo com Jatobá (2003), a região está inserida no embasamento cristalino, em um dos mais destacados compartimentos regionais do relevo nordestino, o Planalto da Borborema, apresentando altitudes entre 500 e $800 \mathrm{~m}$. Os solos dominantes são Planossolos Nátricos e Solódicos, que ocupam as posições pouco movimentadas e rebaixadas, com relevo suave ondulado, interrompido por serras e serrotes, cujos solos constituídos são os Neossolos Litólicos, que margeiam a área, e por estreitas faixas de Neossolos Flúvicos, relacionadas com os aluviões dos rios e riachos que formam a bacia do rio Capibaribe. 
A área é explorada com pecuária extensiva e com alguma agricultura de subsistência nos pequenos aluviões que cortam a região, sendo caracterizada por uma vegetação de caatinga hiperxerófila arbustiva pouco densa a aberta. A retirada de lenha, principalmente para a produção de carvão em fornos trincheira, é prática comum, contribuindo para a degradação da biodiversidade e dos solos da região.

Os locais de amostragem dos ambientes conservados, moderadamente degradados e degradados foram definidos com base em interpretação preliminar de imagens de satélite do sensor ASTER (Advanced Spacebone Thermal Emission and Reflection Radiometer) em composição colorida R2-G3-B1, nas quais cada pixel corresponde a $15 \mathrm{~m}$, adquiridas em 6/11/2003, processadas no GEOSERE-RRS (Recife Receiving Station) da Universidade Federal Rural de Pernambuco, utilizando-se o software ENVI, com aplicações de técnicas de realce para melhorar o contraste das bandas espectrais. A partir desta préseleção, observou-se, em campo, o grau de degradação dos solos (ocorrência de erosão, taxa de recobrimento, encrostamento) e da vegetação (densidade, altura, ocorrência de espécies indicadoras) para a escolha dos ambientes. Em cada ambiente, foram estabelecidas quatro parcelas de $10 \times 20 \mathrm{~m}$. Foram coletados doze perfis de solos, sendo quatro em área cercada, raramente pastejada, caracterizada por vegetação de caatinga arbustiva densa (ambiente conservado); quatro em área com vegetação mais aberta, apresentando erosão hídrica moderada (ambiente moderadamente degradado), e quatro em área caracterizada por vegetação de caatinga aberta, esparsa, com alta intensidade de pastoreio e ocorrência de severa erosão hídrica (ambiente degradado). Para caracterizar a vegetação, os indivíduos foram classificados em três estratos ou classes de altura: 3indivíduos com alturas superiores a 3,0 m (lenhosas altas), amostrados em toda a área da parcela $\left(200 \mathrm{~m}^{2}\right)$; 2- indivíduos com alturas variando de 0,51 a 3,0 m (lenhosas baixas), amostrados em subárea de $100 \mathrm{~m}^{2}$; 1 - indivíduos com alturas iguais ou inferiores a $0,5 \mathrm{~m}$ (estrato da regeneração), amostrados em 18 miniparcelas de $25 \times 50 \mathrm{~cm}$. Os solos foram caracterizados morfologicamente de acordo com Lemos \& Santos (1996), enquanto as amostras foram coletadas por horizonte para realização das análises físicas, químicas e mineralógicas, segundo Embrapa (1997).

O levantamento florístico, realizado no período de maio a agosto de 2004, visou identificar os indivíduos presentes nas parcelas. As espécies identificadas foram incorporadas ao herbário Prof. Vasconcelos Sobrinho (Departamento de Botânica da Universidade Federal Rural de Pernambuco) e ao herbário da Empresa Pernambucana de Pesquisa Agropecuária - IPA. Neste trabalho, foram utilizados parâmetros fitossociológicos adaptados às condições da caatinga, conforme método proposto por Rodal et al. (1992): densidade absoluta e relativa das espécies nos três estratos verticais.
A Densidade Absoluta (DA) é a medida que expressa o número de indivíduos de determinada espécie por unidade de área (em geral por hectare, para lenhosas, e por metro quadrado, para herbáceas), calculada pela expressão:

$$
\mathrm{DA}=\mathrm{n} \times \mathrm{U} / \mathrm{A}
$$

em que n: número de indivíduos da espécie analisada; U: área $\left(10.000 \mathrm{~m}^{2}\right.$ ou $\left.1 \mathrm{~m}^{2}\right)$; e A: área amostrada $\left(\mathrm{m}^{2}\right)$ (Rodal et al., 1992).

A Densidade Relativa (DR) representa a percentagem de indivíduos de determinada espécie com relação ao total de indivíduos amostrados.

$$
\mathrm{DR}=100 \times \mathrm{n} / \mathrm{N}
$$

em que n: número de indivíduos da espécie analisada; e N: número total de indivíduos (Rodal et al. 1992).

Para avaliar a relação entre solo e vegetação, buscando identificar características dos solos relacionadas com a maior ou menor susceptibilidade aos processos de degradação, efetuou-se inicialmente uma análise multivariada da variância, a fim de detectar diferenças entre as situações consideradas, seguida de Análise de Correlação Canônica dos dados obtidos nas análises, utilizando o Programa SAS Statistical Package (SAS, 1999), sendo as médias comparadas pelo teste $\mathrm{F}(\mathrm{P}<0,01)$. As médias dos índices de vegetação e atributos do solo para cada ambiente foram comparadas utilizando o Proc ttest de Cochran a $5 \%$. Análises de regressão entre características e atributos dos solos foram também obtidas (SAS, 1999).

\section{RESULTADOS E DISCUSSÃO}

\section{Características da vegetação}

No terceiro estrato vertical, Aspidosperma pyrifolium (pereiro) e Ceasalpinia pyramidalis (catingueira) ocorreram nos ambientes conservados e moderadamente degradados (Quadro 1). Para A. pyrifolium, a densidade foi maior na área conservada, ocorrendo o inverso com $C$. pyramidalis, cuja densidade aumentou no ambiente com degradação moderada. Andrade et al. (2005), analisando a cobertura de duas fitofisionomias de caatinga, com diferentes históricos de uso, no município de São João do Cariri - PB, verificaram que as três espécies que apresentaram maior densidade relativa, no ambiente em melhor estado de conservação, foram Croton sonderianus (39,3\%), Caesalpinia pyramidalis (30,2\%) e Aspidosperma pyrifolium (15,0 \%).

Não foi registrado indivíduo no terceiro estrato vertical para o ambiente degradado. Os solos, nestas áreas, apresentavam-se severamente erodidos, com horizonte superficial pouco profundo, seguido de 
Quadro 1. Número de espécies amostradas, densidades absolutas e espécies com maiores valores de densidade relativa, por classe de altura, em ambientes com diferentes intensidades de degradação, em Jataúba (PE)

\begin{tabular}{|c|c|c|c|c|}
\hline & $\begin{array}{l}\text { Classe de } \\
\text { altura }\end{array}$ & $\begin{array}{l}\text { Número de } \\
\text { espécies }\end{array}$ & $\begin{array}{l}\text { Densidade } \\
\text { absoluta }\end{array}$ & $\begin{array}{l}\text { Espécies com maiores } \\
\text { densidades relativas }\end{array}$ \\
\hline \multirow[t]{3}{*}{$\begin{array}{l}\text { Ambiente } \\
\text { conservado }\end{array}$} & $>3,0 \mathrm{~m}$ & 7 & $\begin{array}{l}688 \mathrm{a} \\
\text { Indivíduos ha-1 }\end{array}$ & $\begin{array}{l}\text { Mimosa ophthalmocentra }(40 \%) \\
\text { Aspidosperma pyryfolium }(30,9 \%), \\
\text { Caesalpinia pyramidalis }(20 \%)\end{array}$ \\
\hline & 0,51 a $3,0 \mathrm{~m}$ & 16 & $\begin{array}{l}36.150 \mathrm{a} \\
\text { Indivíduos ha-1 }\end{array}$ & $\begin{array}{l}\text { Neoglaziovia variegata }(75 \%) \\
\text { Cordia leucocephala }(7,8 \%)\end{array}$ \\
\hline & $\leq 0,5 \mathrm{~m}$ & 31 & $\begin{array}{l}196,2 \mathrm{a} \\
\text { Indivíduos } \mathrm{m}^{-2}\end{array}$ & $\begin{array}{l}\text { Evolvulus filipes }(35,5 \%), \\
\text { Portulaca elatior }(14,9 \%), \\
\text { Diodia apiculata }(14,8 \%)\end{array}$ \\
\hline \multirow{3}{*}{$\begin{array}{l}\text { Ambiente } \\
\text { moderadamente } \\
\text { degradado }\end{array}$} & $>3,0 \mathrm{~m}$ & 5 & $\begin{array}{l}\text { 738a } \\
\text { Indivíduos ha-1 }\end{array}$ & $\begin{array}{l}\text { Caesalpinia pyramidalis }(67,8 \%) \\
\text { Aspidosperma pyryfolium }(17 \%)\end{array}$ \\
\hline & 0,51 a $3,0 \mathrm{~m}$ & 14 & $\begin{array}{l}12.075 \mathrm{~b} \\
\text { Indivíduos ha-1 }\end{array}$ & $\begin{array}{l}\text { Bromelia laciniosa }(28,4 \%), \\
\text { Aspidosperma pyryfolium }(19,5 \%), \\
\text { Caesalpinia pyramidalis }(12,6 \%)\end{array}$ \\
\hline & $\leq 0,5 \mathrm{~m}$ & 33 & $\begin{array}{l}154,9 \mathrm{a} \\
\text { Indivíduos } \mathrm{m}^{\cdot 2}\end{array}$ & $\begin{array}{l}\text { Evolvulus filipes }(19 \%), \\
\text { Cyperus uncynulatus }(11,5 \%), \\
\text { Tragus berteronianus }(10,9 \%)\end{array}$ \\
\hline \multirow{3}{*}{$\begin{array}{l}\text { Ambiente } \\
\text { degradado }\end{array}$} & $>3,0 \mathrm{~m}$ & - & - & - \\
\hline & 0,51 a $3,0 \mathrm{~m}$ & 12 & $\begin{array}{l}6.550 \mathrm{c} \\
\text { Indivíduos ha-1 }\end{array}$ & $\begin{array}{l}\text { Caesalpinia pyramidalis }(31,8 \%) \\
\text { Sida galheirensis }(18 \%), \\
\text { Croton blanchetianus }(13,4 \%)\end{array}$ \\
\hline & $\leq 0,5 \mathrm{~m}$ & 29 & $\begin{array}{l}212,4 \mathrm{a} \\
\text { Indivíduos } \mathrm{m}^{-2}\end{array}$ & $\begin{array}{l}\text { Aristida setifolia }(28,6 \%), \\
\text { Evolvulus filipes }(17,5 \%), \\
\text { Cyperus uncynulatus }(10,3 \%)\end{array}$ \\
\hline
\end{tabular}

Médias dos valores de densidade absoluta para cada classe de altura seguidas de mesma letra, na coluna, não diferem estatisticamente entre si a $5 \%$ pelo teste t de Cochran \& Cox.

horizonte subsuperficial muito argiloso, com teores de $\mathrm{Na}$ elevados e permeabilidade muito lenta, constituindo uma barreira à penetração da água, com sérias limitações no período seco (déficit hídrico) e no chuvoso (excesso de água e falta de oxigenação). Estas restrições contribuem para dificultar a regeneração e o desenvolvimento das plantas, particularmente das espécies lenhosas de porte alto.

$\mathrm{O}$ ambiente de caatinga conservada apresentou maior densidade absoluta de espécies para o segundo estrato vertical (lenhosas baixas), em relação aos ambientes degradados (Quadro 1). Neoglaziovia variegata (caroá) e Cordia leucocephala (moleque duro) estiveram presentes apenas no ambiente conservado. Essas espécies são indicadoras de ambientes menos antropizados (Vasconcelos Sobrinho,1982; Santos et al., 1992; Sampaio et al., 1998). C. pyramidalis, Bromelia laciniosa (macambira), A. pyrifolium, Sida galheirensis (malva branca) e J. ribifolia (pinhão) ocorreram nos três ambientes, sendo maiores as densidades dessas espécies nas áreas mais degradadas. Segundo Araújo Filho \& Carvalho (1996), a malva branca (Sida sp.) é um dos indicadores mais importantes até agora identificados no caso de uma sucessão secundária a partir de estádios mais regressivos, e suas populações tendem a aumentar nas fases iniciais com a intensificação do processo de degradação.

No primeiro estrato vertical, Evolvulus filipes, Portulaca elatior e Diodia apiculata ocorreram nos três ambientes, com maiores densidades para a área conservada. Aristida setifolia (capim-panasco) e Tragus berteronianus (carrapicho-de-ovelha) ocorreram no ambiente moderadamente degradado e no degradado. As densidades absolutas neste estrato tenderam a aumentar nos ambientes degradados, embora sem significância estatística. Esses resultados são esperados, uma vez que o componente herbáceo é caracterizado pela presença marcante de espécies heliófitas, que predominam nos sítios de caatingas abertas (Araújo Filho \& Carvalho, 1996).

As densidades absolutas para plantas lenhosas observadas no ambiente conservado em Jataúba (36.838 ind. ha-1) foram muito baixas. Santos et al. (1992) encontraram valores 2,36 vezes mais elevados (87.120 ind. ha-1) para um Planossolo Nátrico em Parnamirim, PE, embora a densidade de plantas 
herbáceas $\left(15,7\right.$ ind. $\left.\mathrm{m}^{-2}\right)$ tenha sido muito inferior à de Jataúba (12,3 vezes menor). Estas comparações devem ser interpretadas com cautela, pois a amostragem de lenhosas e sublenhosas em Parnamirim incluiu plantas de todas as alturas, a partir do nível do solo, o que não ocorreu em Jataúba. Valores de densidade baixos para lenhosas (3.810 ind. ha-1) também foram observados por Alcoforado-Filho et al. (2003), em um Argissolo Amarelo de Caruaru, PE, em condições climáticas e edáficas mais favoráveis que as de Jataúba, para vegetação de caatinga hipoxerófila e utilizando critérios de amostragem menos abrangentes, incluindo plantas com diâmetro médio de caule superior ou igual a $3 \mathrm{~cm}$ e altura igual ou superior a $1 \mathrm{~m}$. Segundo Araújo et al. (1995), os valores dos índices de vegetação, além de refletirem as diferentes características bióticas e abióticas do ambiente e suas interações, são influenciados pelos critérios de inclusão adotados para amostrar a vegetação. Em geral, o estabelecimento de limites de inclusão menos abrangentes resulta em densidades menores e o inverso ocorre com limites mais abrangentes.

\section{Características dos solos}

Com base nas descrições morfológicas e interpretação dos dados analíticos, os solos foram classificados até o quinto nível, com fases, segundo os critérios definidos no Sistema Brasileiro de Classificação de Solos (Embrapa, 2006).

Os solos do ambiente conservado foram assim classificados: perfis CJ-1 e CJ-4 como Planossolo Háplico eutrófico solódico, textura média cascalhenta/ argilosa, A moderado, fase caatinga hiperxerófila, relevo suave ondulado; o perfil CJ-2 como Planossolo Háplico eutrófico típico, textura média cascalhenta/ argilosa, A fraco, fase caatinga hiperxerófila, relevo suave ondulado; e o perfil CJ-3 como Planossolo Háplico eutrófico solódico textura arenosa cascalhenta/argilosa A moderado, fase caatinga hiperxerófila, relevo suave ondulado.

Os solos apresentam erosão laminar ligeira e são imperfeitamente drenados, com horizonte superficial eluvial de textura franco-arenosa cascalhenta, estrutura maciça moderadamente coesa e fraca pequena granular ou em blocos subangulares. O teor médio de silte mais areia fina no horizonte superficial é de $428 \mathrm{~g} \mathrm{~kg}^{-1}$ de solo. Apresentam transição abrupta para um horizonte Bt ou Btn adensado e com altas percentagens de argila, estrutura grande a muito grande, prismática ou colunar e uma mudança textural abrupta, resultante de processos de translocação de argila para o Bt, destruição de argila dos horizontes $\mathrm{A}$ ou E, e, ou, perda por erosão diferencial. Esta mudança textural, seguida de horizonte Bt com permeabilidade muito lenta, constitui uma barreira à penetração da água, sendo responsável pela grande restrição à drenagem e pela alta susceptibilidade à erosão destes solos (Quadro 2).
Apresentam horizontes superficiais relativamente profundos (A + E com $32 \mathrm{~cm}$, em média), favorecendo o melhor desenvolvimento da vegetação, que apresenta muitas raízes nos horizontes A e E, sendo raras no horizonte Btn, como pode ser observado na figura 1. Crostas superficiais são pouco espessas $(0,5 \mathrm{~cm})$ e ocorrem em pequena extensão na área.

A densidade global variou de 1,33 a 1,89 t m $\mathrm{m}^{-3}$, sendo os maiores valores encontrados nos horizontes subsuperficiais (Quadro 3). O teor de água disponível é máximo nos horizontes subsuperficiais, chegando a ser duas vezes maior que nos horizontes sobrejacentes, graças aos altos valores de argila nestes horizontes. A porosidade total é sempre menor no horizonte subsuperficial dos perfis analisados, em virtude da alta dispersão provocada pela presença do Na.

Os solos apresentam alta saturação por bases, com predominância de cálcio e magnésio nos horizontes superficiais, e magnésio e Na no horizonte Btn. Têm reação moderadamente ácida a praticamente neutra nos horizontes superficiais, onde o $\mathrm{Ca}^{2+}$ e $\mathrm{Mg}^{2+}$ estão sendo substituídos pelo $\mathrm{H}^{+}$, tornando-se praticamente neutra a moderadamente alcalina no horizonte Btn (Quadro 4).

No ambiente moderadamente degradado, os solos foram predominantemente Planossolos Nátricos. O perfil MJ-1 foi classificado como Planossolo Nátrico órtico típico textura média cascalhenta/argilosa cascalhenta A moderado, fase caatinga hiperxerófila relevo suave ondulado; o perfil MJ-2, como Planossolo Nátrico órtico típico textura média (leve)/argilosa $\mathrm{A}$ moderado, fase caatinga hiperxerófila relevo suave ondulado; o perfil MJ-3, como Planossolo Háplico eutrófico solódico, textura média/argilosa A moderado fase caatinga hiperxerófila relevo suave ondulado; e o perfil MJ-4, como Planossolo Nátrico órtico vertissólico salino textura média/argilosa A moderado fase caatinga hiperxerófila, relevo plano.

Os solos apresentam características morfológicas semelhantes às dos solos do ambiente conservado, porém com menor quantidade de cascalho no horizonte superficial (à exceção do perfil MJ-1), e um horizonte Btn de permeabilidade lenta precedido por uma transição abrupta, embora sem apresentar mudança textural abrupta (exceto o MJ-2). O teor médio de silte mais areia fina no horizonte superficial é de $470 \mathrm{~g} \mathrm{~kg}^{-1}$ de solo (Quadro 2). A ocorrência de erosão laminar moderada e em sulcos rasos e ocasionais pode ser constatada pela redução da espessura do horizonte superficial (Figura 2), quando comparada à dos solos da área conservada (horizonte A com média de $10 \mathrm{~cm}$ ). Observou-se a formação de crostas superficiais com espessura de $1 \mathrm{~cm}$, o que dificulta ainda mais a infiltração da água das chuvas.

A densidade global variou de 1,48 a 1,91 $\mathrm{t} \mathrm{m}^{-3}$, tendo sido os maiores valores encontrados nos horizontes subsuperficiais (Quadro 3). O teor de água disponível foi máximo nos horizontes subsuperficiais, e maior que nos solos das áreas conservadas, graças aos altos 
Quadro 2. Composição granulométrica, argila dispersa em água, grau de floculação e relação silte/argila de solos de ambientes conservados, moderadamente degradados e degradados, em Jataúba, PE

\begin{tabular}{|c|c|c|c|c|c|c|c|c|c|c|c|}
\hline Hor. & Prof. & Calhau & Cascalho & TFSA & $\begin{array}{l}\text { Areia } \\
\text { grossa }\end{array}$ & $\begin{array}{l}\text { Areia } \\
\text { fina }\end{array}$ & Silte & Argila & $\begin{array}{c}\text { Argila } \\
\text { dispersa } \\
\text { em água }\end{array}$ & $\begin{array}{c}\text { Grau de } \\
\text { flocu- } \\
\text { lação }\end{array}$ & $\begin{array}{c}\text { Silte/ } \\
\text { argila }\end{array}$ \\
\hline & $\mathrm{cm}$ & 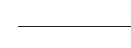 & $\%$ & - & 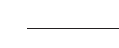 & g & $\mathrm{kg}^{-1}$ de & solo - & 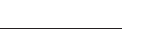 & $\%$ & \\
\hline \multicolumn{12}{|c|}{ Ambiente conservado } \\
\hline \multicolumn{12}{|c|}{ Perfil CJ-1: Planossolo Háplico eutrófico solódico } \\
\hline A & $0-17$ & 2 & 16 & 82 & 450 & 260 & 150 & 140 & 100 & 28 & 1,07 \\
\hline $\mathrm{E}$ & $17-29$ & 13 & 36 & 51 & 490 & 250 & 120 & 140 & 90 & 36 & 0,86 \\
\hline Btn & $29-50$ & - & 10 & 90 & 240 & 110 & 90 & 560 & 370 & 34 & 0,16 \\
\hline \multicolumn{12}{|c|}{ Perfil CJ-2: Planossolo Háplico eutrófico típico } \\
\hline A & $0-20$ & 1 & 12 & 87 & 290 & 400 & 150 & 160 & 70 & 56 & 0,94 \\
\hline $\mathrm{E}$ & $20-34$ & 9 & 29 & 62 & 340 & 280 & 130 & 250 & 150 & 40 & 0,52 \\
\hline Btn & $34-52$ & 1 & 8 & 91 & 180 & 190 & 50 & 580 & 220 & 62 & 0,09 \\
\hline \multicolumn{12}{|c|}{ Perfil CJ-3:Planossolo Háplico eutrófico solódico } \\
\hline A & $0-14$ & 2 & 23 & 75 & 590 & 220 & 90 & 100 & 70 & 30 & 0,90 \\
\hline $\mathrm{E}$ & $14-28$ & 10 & 40 & 50 & 680 & 160 & 70 & 90 & 40 & 56 & 0,78 \\
\hline Btn & $28-71$ & - & 8 & 92 & 330 & 110 & 50 & 510 & 450 & 12 & 0,10 \\
\hline \multicolumn{12}{|c|}{ Perfil CJ-4: Planossolo Háplico eutrófico solódico } \\
\hline A & $0-16$ & 13 & 26 & 61 & 440 & 290 & 150 & 120 & 90 & 25 & 1,25 \\
\hline $\mathrm{E}$ & $16-38$ & 2 & 23 & 75 & 580 & 180 & 110 & 130 & 90 & 31 & 0,85 \\
\hline Btn & $38-60$ & - & 8 & 92 & 220 & 90 & 140 & 550 & 430 & 22 & 0,25 \\
\hline \multicolumn{12}{|c|}{ Ambiente moderadamente degradado } \\
\hline \multicolumn{12}{|c|}{ Perfil MJ-1: Planossolo Nátrico órtico típico } \\
\hline A & $0-12$ & 18 & 37,5 & 44,5 & 300 & 300 & 190 & 210 & 150 & 28 & 0,90 \\
\hline Btn & $12-43$ & 3,5 & 15,5 & 81 & 400 & 130 & 120 & 350 & 230 & 34 & 0,34 \\
\hline \multicolumn{12}{|c|}{ Perfil MJ-2: Planossolo Nátrico órtico típico } \\
\hline Ap & $0-15$ & 2 & 10 & 88 & 330 & 320 & 190 & 160 & 120 & 25 & 1,19 \\
\hline Btn1 & $15-42$ & 1 & 6 & 93 & 310 & 210 & 140 & 340 & 270 & 20 & 0,41 \\
\hline Btn2 & $42-70$ & 2 & 6 & 92 & 280 & 180 & 160 & 380 & 270 & 29 & 0,42 \\
\hline \multicolumn{12}{|c|}{ Perfil MJ-3: Planossolo Háplico eutrófico solódico } \\
\hline A & $0-7$ & 1 & 11 & 88 & 260 & 230 & 210 & 300 & 200 & 33 & 0,70 \\
\hline $\mathrm{Bt}$ & $7-39$ & - & 2 & 98 & 340 & 140 & 140 & 380 & 270 & 29 & 0,37 \\
\hline $\mathrm{BCn}$ & $39-55$ & - & 4 & 96 & 230 & 240 & 200 & 330 & 200 & 39 & 0,61 \\
\hline \multicolumn{12}{|c|}{ Perfil MJ-4: Planossolo Nátrico órtico vertissólico salino } \\
\hline A & $0-6$ & 1 & 6 & 93 & 200 & 220 & 220 & 360 & 250 & 30 & 0,61 \\
\hline Btn1 & $6-33$ & - & 2,5 & 97,5 & 190 & 210 & 140 & 460 & 400 & 13 & 0,30 \\
\hline Btn2 & $33-65$ & - & 1,5 & 98,5 & 170 & 230 & 130 & 470 & 400 & 15 & 0,28 \\
\hline \multicolumn{12}{|c|}{ Ambiente degradado } \\
\hline \multicolumn{12}{|c|}{ Perfil DJ-1: Planossolo Háplico eutrófico solódico } \\
\hline A & $0-20$ & 2 & 14 & 84 & 300 & 410 & 170 & 120 & 50 & 58 & 1,42 \\
\hline $\mathrm{E}$ & $20-42$ & 13 & 47 & 40 & 360 & 330 & 160 & 150 & 60 & 60 & 1,07 \\
\hline Btn & $42-55$ & 1 & 4 & 95 & 300 & 200 & 60 & 440 & 330 & 25 & 0,14 \\
\hline \multicolumn{12}{|c|}{ Perfil DJ-2: Planossolo Nátrico órtico salino } \\
\hline A & $0-6$ & 1 & 9 & 90 & 220 & 380 & 230 & 170 & 120 & 29 & 1,35 \\
\hline Btn & $6-31$ & - & 4 & 96 & 350 & 140 & 140 & 370 & 260 & 30 & 0,38 \\
\hline $\mathrm{Cn}$ & $31-80+$ & 1 & 11 & 88 & 390 & 210 & 110 & 290 & 200 & 31 & 0,38 \\
\hline \multicolumn{12}{|c|}{ Perfil DJ-3: Planossolo Nátrico órtico salino } \\
\hline A & $0-9$ & - & 10 & 90 & 300 & 320 & 200 & 180 & 130 & 28 & 1,11 \\
\hline Btn & $9-40$ & - & 3 & 97 & 320 & 240 & 80 & 360 & 260 & 28 & 0,22 \\
\hline $\mathrm{BCn}$ & $40-64$ & - & 1 & 99 & 270 & 240 & 140 & 350 & 270 & 23 & 0,40 \\
\hline $\mathrm{Cn}$ & $64-100$ & - & 4 & 96 & 250 & 230 & 170 & 350 & 280 & 20 & 0,48 \\
\hline \multicolumn{12}{|c|}{ Perfil DJ-4: Planossolo Nátrico órtico típico } \\
\hline A & $0-19$ & 2 & 8 & 90 & 300 & 400 & 140 & 160 & 110 & 31 & 0,88 \\
\hline Btn & $19-54$ & - & 2 & 98 & 340 & 260 & 50 & 350 & 300 & 14 & 0,14 \\
\hline $\mathrm{BCn}$ & $54-75$ & 1 & 3 & 96 & 240 & 280 & 90 & 390 & 310 & 20 & 0,23 \\
\hline
\end{tabular}




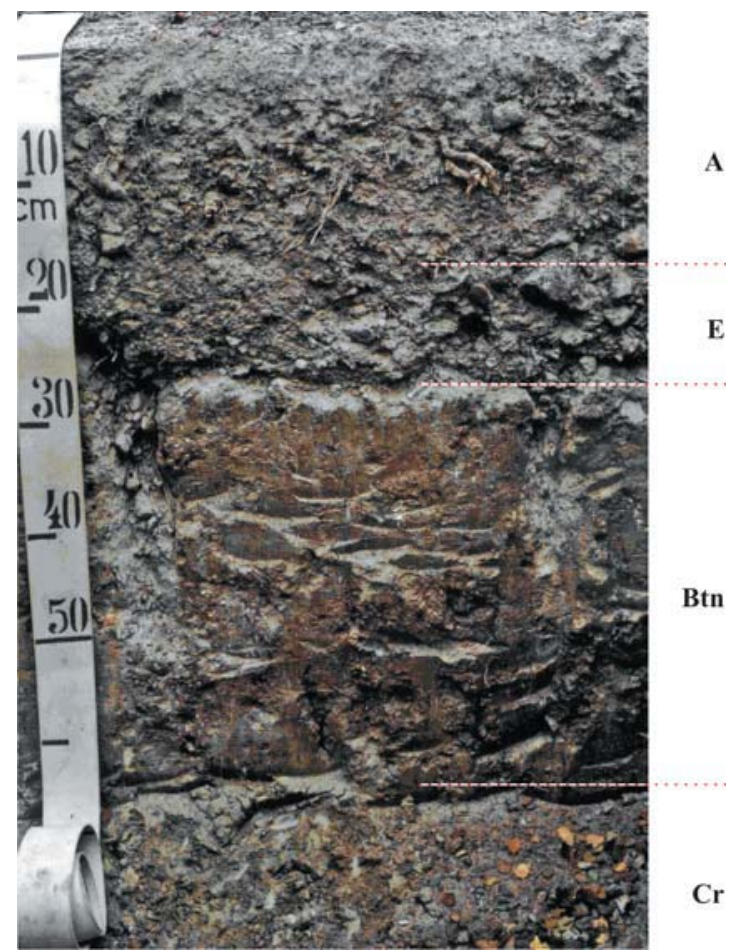

Figura 1. Perfil CJ-3 - Planossolo Háplico eutrófico solódico, em ambiente conservado de Jataúba, PE.

valores de argila nestes horizontes. A condução de água é interrompida no horizonte subsuperficial dos perfis analisados (com exceção do MJ3), em virtude da alta dispersão das argilas, provocada pela presença do Na.

O $\mathrm{Na}$, presente em altas concentrações nos horizontes subsuperficiais (Quadro 4), aliado à alta percentagem de argila, causa a dispersão da mesma, dificultando a drenagem dos solos e a penetração de raízes, que são raras no horizonte Btn. Os solos apresentam maiores conteúdos de cátions trocáveis e $\mathrm{N}$ total. Os teores mais elevados de CO, se comparados àqueles observados nos solos das áreas conservadas e intensamente degradadas da região, são devidos aos teores de argila mais altos no horizonte A, que protegem a matéria orgânica da decomposição mais intensa. A reação é praticamente neutra a moderadamente alcalina nos horizontes superficiais e moderada a fortemente alcalina nos subsuperficiais, que apresentam PST mais elevada.

No ambiente degradado, o perfil DJ-1 foi classificado como Planossolo Háplico eutrófico solódico textura média (leve) cascalhenta/argilosa A fraco fase caatinga hiperxerófila, relevo plano; os perfis DJ-2 e DJ-3 como Planossolo Nátrico órtico salino, textura média (leve)/argilosa A fraco, fase caatinga hiperxerófila relevo plano; e o perfil DJ-4 como Planossolo Nátrico órtico típico textura média (leve)/ argilosa A fraco fase caatinga hiperxerófila relevo suave ondulado.
Os solos apresentam estrutura maciça moderadamente coesa a coesa e crostas superficiais mais espessas, variando de 1 a $2 \mathrm{~cm}$, ocupando quase $50 \%$ da superfície da área, dificultando a infiltração da água das chuvas. A pequena espessura do horizonte A, os elevados teores de silte mais areia fina observados no quadro 2 (média de $563 \mathrm{~g} \mathrm{~kg}^{-1}$ ) e a mudança textural abrupta próxima à superfície contribuem para maior susceptibilidade à erosão, descrita como erosão laminar moderada a severa, associada à presença de sulcos rasos e freqüentes. A figura 3 representa o perfil de área bastante degradada, recoberta por capim-panasco (Aristida setifolia).

A reação é moderadamente ácida a praticamente neutra nos horizontes superficiais, pela substituição de $\mathrm{Ca}^{2+}$ e $\mathrm{Mg}^{2+}$ pelo $\mathrm{H}^{+}$, tornando-se moderada a fortemente alcalina nos subsuperficiais, que apresentam os maiores percentuais de Na trocável (Quadro 4). Os conteúdos de CO e N são muito baixos.

Quanto à composição mineralógica, os solos são semelhantes em todas as áreas estudadas. Merece destaque a presença de micas parcialmente alteradas (biotita e muscovita), nas frações areias grossa e fina dos horizontes superficiais, que podem contribuir para o aumento da susceptibilidade à erosão e encrostamento. A fração silte dos solos é composta basicamente por quartzo, feldspato, mica e calcita, enquanto a fração argila é constituída por minerais de argila do grupo das caulinitas, micas e esmectitas. A presença expressiva de argilas do grupo das esmectitas contribui para a baixa permeabilidade dos horizontes subsuperficiais.

Alguns atributos dos solos apresentaram variações para os ambientes com diferentes intensidades de degradação. O quadro 5 reúne as características dos solos que podem ser utilizadas como indicadores da degradação associada a processos de desertificação nestas áreas, identificando a magnitude e a direção das variações.

Dentre os indicadores físicos, destacaram-se: a ocorrência e intensidade dos processos de erosão, a redução da espessura dos horizontes superficiais dos perfis e a formação de crostas na superfície, que podem ser visualizados e quantificados com facilidade numa avaliação preliminar em campo; além dos teores de cascalho e de silte mais areia fina nos horizontes superficiais, a densidade do solo em superfície e a condutividade hidráulica subsuperficial. Estes indicadores estão relacionados com o arranjo das partículas sólidas e poros e ocorrência de erosão, refletindo, primariamente, limitações ao crescimento de raízes, emergência de plântulas, infiltração ou movimento de água dentro do perfil.

Os valores de densidade global do horizonte A aumentaram nas áreas com degradação, embora sem significância estatística, provavelmente pela ação do pisoteio animal nestas áreas. A condutividade hidráulica saturada diminuiu com o aumento da 
Quadro 3. Densidade, porosidade, parâmetros hídricos e condutividade hidráulica saturada de solos de ambientes conservados, moderadamente degradados e degradados, em Jataúba, PE

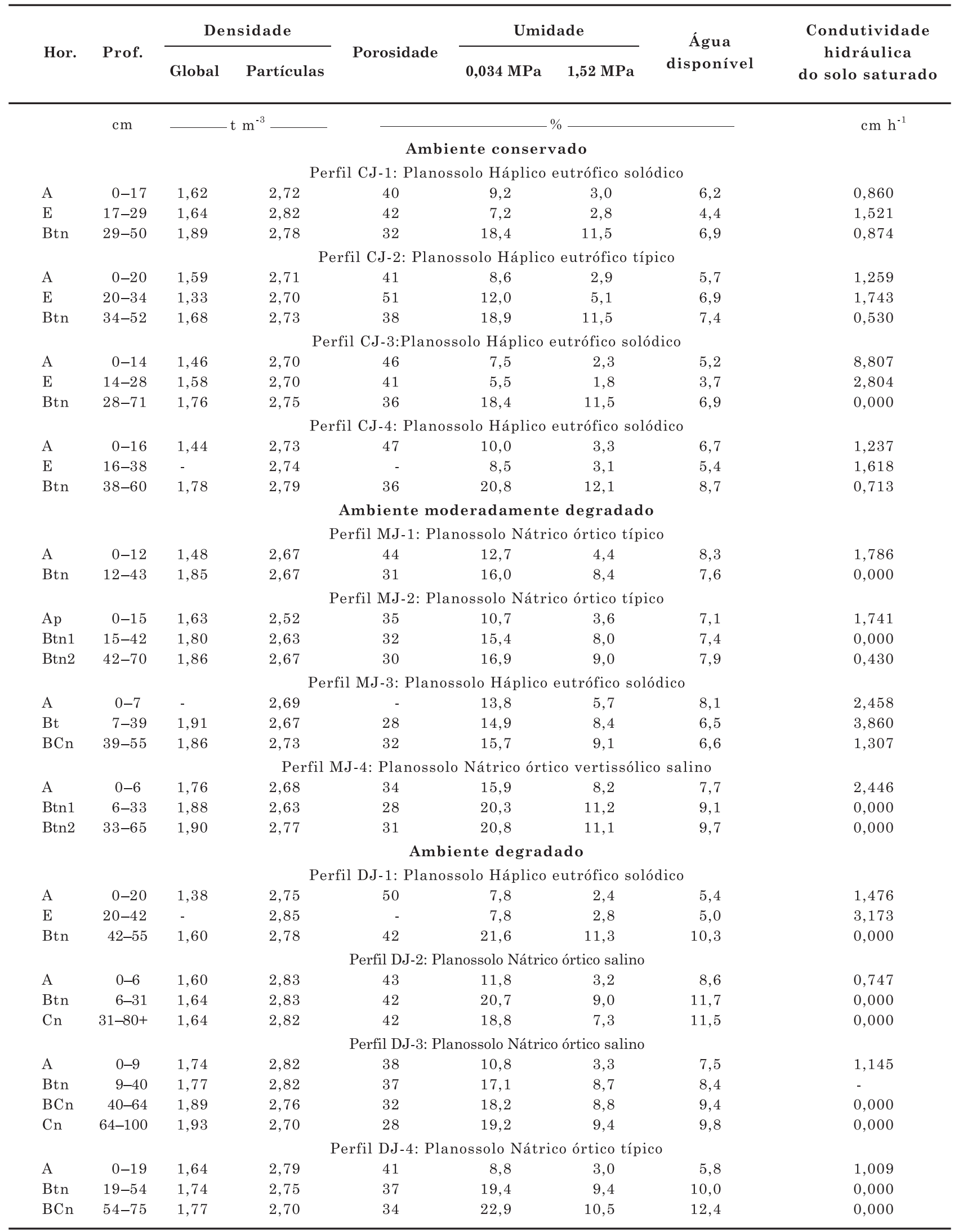


Quadro 4. Propriedades químicas dos solos de áreas conservadas, moderadamente degradadas e degradadas em Jataúba - PE

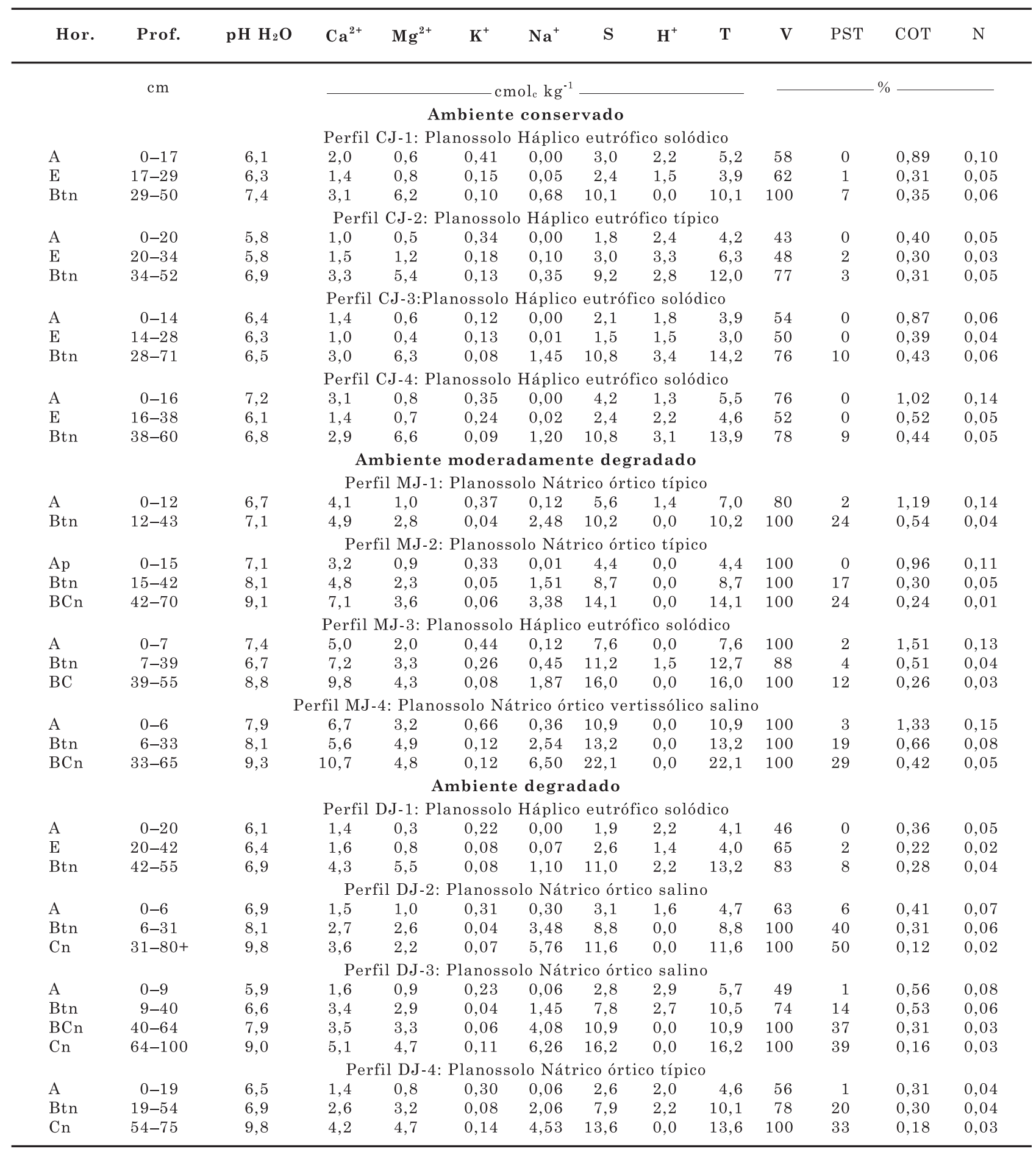

profundidade e com o ambiente (Quadros 3 e 5). Nas áreas intensamente degradadas, a condução de água no perfil cessou completamente nos horizontes subsuperficiais, que apresentavam PST mais elevada (Quadro 4). A alta percentagem de saturação por $\mathrm{Na}$ dificulta o desenvolvimento normal das raízes e contribui para degradação da estrutura dos solos, em conseqüência da dispersão das argilas, o que retarda ou mesmo impede a infiltração da água no perfil. A percentagem de água disponível no solo está diretamente relacionada com a condutividade hidráulica do solo no horizonte $B\left(R^{2}=0,80\right)$, apresentando correlação negativa com os valores de PST nos horizontes subsuperficiais $\left(R^{2}=-0,78\right)$. 


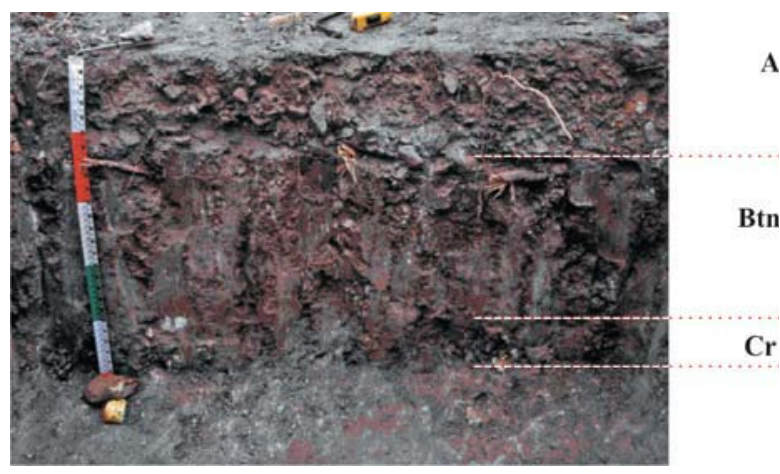

Figura 2. Perfil MJ-1 - Planossolo Nátrico órtico típico, em ambiente moderadamente degradado de Jataúba, PE.

Teores elevados de silte mais areia fina estão associados à maior tendência à formação de crostas superficiais (Roth, 1992; Fox et al., 2004). Estes valores foram significativamente mais elevados nas áreas intensamente degradadas, onde a ocorrência de crostas mais espessas foi significativamente maior, em comparação com os ambientes conservados e moderadamente degradados (Quadro 5).

Os solos dos ambientes degradados, caracterizados por maior erosão, evidenciada pela remoção das camadas superficiais, continham menor quantidade de cascalho nos horizontes A + E, observando-se um $R^{2}=0,79$ entre estes valores e a espessura dos horizontes superficiais. O valor da soma das profundidades de A + E também apresentou correlação direta com os teores de argila no horizonte $\mathrm{B}\left(\mathrm{R}^{2}=0,70\right)$ e inversa com a percentagem de $\mathrm{Na}$ trocável nos horizontes subsuperficiais $\left(\mathrm{R}^{2}=0,62\right)$. Teores mais elevados de cascalho nos horizontes superficiais estão relacionados com maior disponibilidade de água $\left(R^{2}=0,65\right)$, favorecendo o desenvolvimento do estrato lenhoso.

Destacaram-se, dentre os indicadores químicos, os teores de $\mathrm{CO}$ e de $\mathrm{N}$ no horizonte superficial e a percentagem de Na trocável nos horizontes subsuperficiais (Quadro 5). A condição química do solo afeta as relações solo-planta, a disponibilidade de nutrientes e de água para as plantas e outros organismos e algumas condições físicas, tais como, a tendência à formação de crostas, a redução da permeabilidade e a maior intensidade dos processos erosivos (Snakin et al., 1996). O COT, particularmente, mostrou-se eficiente para utilização como indicador da degradação do solo, apresentando diferenças significativas entre os ambientes. Os teores de $\mathrm{CO}$ estão diretamente relacionados com os teores de $\mathrm{N}$ total $\left(\mathrm{R}^{2}=0,88\right)$ e cálcio trocável $\left(\mathrm{R}^{2}=0,67\right)$.

Snakin et al. (1996), definindo critérios para estabelecer o grau de degradação dos solos, utilizaram como indicadores a espessura do horizonte A (percentagem do A removido), a densidade do solo (aumento múltiplo dos valores) e o teor de Na trocável (aumento em percentagem da CTC).

Visando identificar possíveis relações entre características da vegetação nos diferentes estratos verticais avaliados e algumas características dos solos, efetuou-se, inicialmente, uma análise multivariada da variância, a fim de detectar diferenças entre as situações consideradas, seguida de Análise de Correlação Canônica dos dados obtidos nas análises. A técnica das correlações canônicas permite estimar

Quadro 5. Características dos solos de Jataúba que apresentaram variações para os ambientes com diferentes intensidades de degradação associada a processos de desertificação

\begin{tabular}{|c|c|c|c|}
\hline \multirow[b]{2}{*}{ Característica do solo } & \multicolumn{3}{|c|}{ Ambiente } \\
\hline & Conservado & $\begin{array}{l}\text { Moderadamente } \\
\text { degradado }\end{array}$ & Degradado \\
\hline Ocorrência de erosão & $\begin{array}{l}\text { Laminar } \\
\text { ligeira }\end{array}$ & $\begin{array}{c}\text { Laminar moderada, } \\
\text { sulcos rasos } \\
\text { ocasionais }\end{array}$ & $\begin{array}{c}\text { Laminar moderada a } \\
\text { severa, sulcos } \\
\text { rasos freqüentes }\end{array}$ \\
\hline Espessura dos horizontes A + E (cm) & $32 \mathrm{a}$ & $10 \mathrm{~b}(-69 \%)$ & $19 \mathrm{ab}(-41 \%)$ \\
\hline Espessura da crosta superficial (cm) & $0,25 \mathrm{~b}$ & $0,75 \mathrm{ab}(+200 \%)$ & $1,25 \mathrm{a}(+400 \%)$ \\
\hline$\%$ de cascalho em $\mathrm{A}+\mathrm{E}$ & $51 \mathrm{a}$ & $16 b(-68 \%)$ & $22 \mathrm{ab}(-57 \%)$ \\
\hline Silte + Areia fina $\left(\mathrm{g} \mathrm{kg}^{-1}\right)$ & $428 b$ & $470 \mathrm{~b}(+10 \%)$ & $563 \mathrm{a}(+32 \%)$ \\
\hline Densidade global no horizonte A $\left(\mathrm{t} \mathrm{m}^{-3}\right)$ & $1,53 \mathrm{a}$ & $1,62 \mathrm{a}(+6 \%)$ & $1,59 \mathrm{a}(+4 \%)$ \\
\hline Condutividade hidráulica subsuperficial $\left(\mathrm{cm} \mathrm{h}^{-1}\right)$ & $0,53 \mathrm{a}$ & $1,02 \mathrm{a}(+92 \%)$ & $0,00 \mathrm{~b}(-100 \%)$ \\
\hline$\%$ de $\mathrm{C}$ orgânico no horizonte $\mathrm{A}$ & $0,80 \mathrm{~b}$ & $1,25 \mathrm{a}(+56 \%)$ & $0,41 \mathrm{c}(-49 \%)$ \\
\hline$\%$ de N-total no horizonte A & $0,09 \mathrm{ab}$ & $0,13 \mathrm{a}(+44 \%)$ & $0,06 \mathrm{~b}(-33 \%)$ \\
\hline PST nos horizontes subsuperficiais & $7 \mathrm{~b}$ & $19 \mathrm{a}(+171 \%)$ & $27 \mathrm{a}(+286 \%)$ \\
\hline
\end{tabular}

Médias seguidas de mesma letra, nas linhas, não diferem estatisticamente entre si a 5 \% pelo teste t de Cochran \& Cox; Valores entre parênteses indicam a direção (+ aumento; - redução) e a magnitude das variações. 
a máxima correlação entre dois grupos de variáveis (solo e vegetação), compostos por combinações lineares dos vários caracteres que os constituem.

Foram avaliados características e atributos dos solos e da vegetação. As melhores correlações entre variáveis simples serviram como base para selecionar os componentes das matrizes de correlação canônica, formada por 11 variáveis e 12 observações (valor da variável em cada parcela amostrada). Selecionaram-

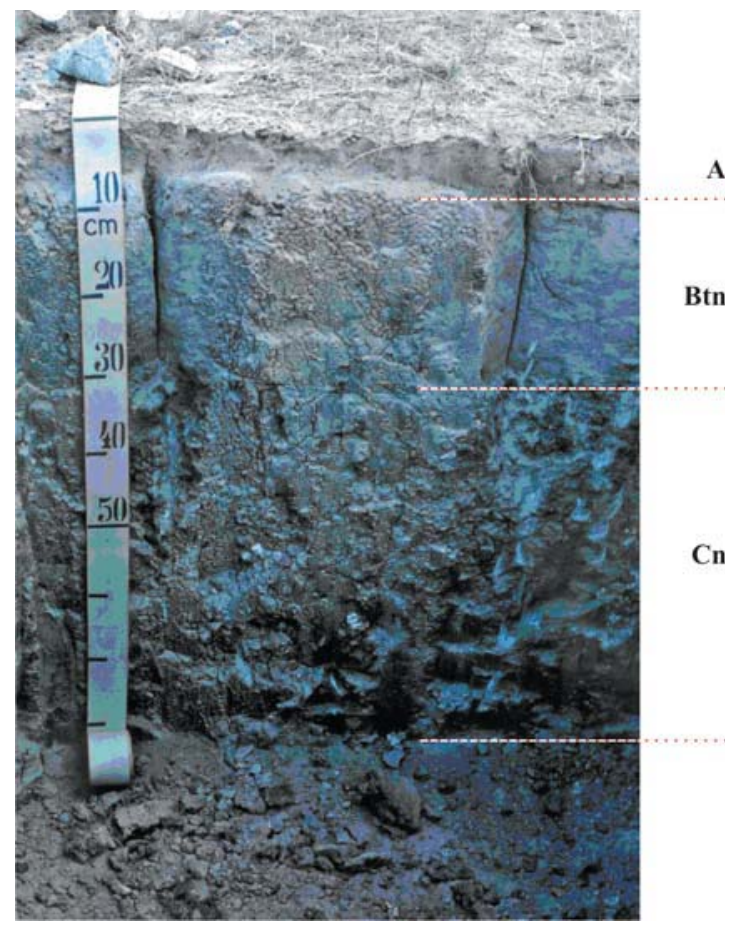

Figura 3. Perfil DJ-2 - Planossolo Nátrico órtico salino, em ambiente degradado de Jataúba, PE. se as variáveis de vegetação: altura média do terceiro estrato vertical (ALT3) e densidade absoluta de plantas no segundo estrato vertical (DA2); as variáveis de solo foram: percentagem de argila no horizonte B (ARGILAB), percentagem de $\mathrm{Na}$ trocável nos horizontes subsuperficiais (PST), CO total (COT), N total (NT), água disponível no perfil à profundidade efetiva (ADPE), espessura dos horizontes A + E (ESPAE), percentagem de cascalho no perfil (CASCALHO), percentagem de silte e areia fina no horizonte superficial (SILTEAF) e condutividade hidráulica saturada no horizonte B (CONDHB), cujas médias e desvios padrão são mostrados no quadro 6 .

A análise multivariada da variância apontou diferenças significativas entre os autovalores ( $\mathrm{F}<0,0025)$ pelo teste lambda de Wilks. Observa-se que 99 \% da variância são explicados pela função 1 (correlação elevada ao quadrado), enquanto a função 2 explica 98 \% (Quadro 6).

Apenas o primeiro par canônico apresentou diferença significativa a $1 \%$, mostrando existir dependência entre as características de vegetação e solo consideradas. O segundo par canônico não foi significativo e não será objeto de discussão. As associações entre os grupos de variáveis vegetação - solo podem ser estabelecidas da seguinte forma: existe uma relação inversa entre a percentagem de Na trocável, o teor de silte mais areia fina, e relação direta entre percentagem de argila no $B$, percentagem de cascalho no perfil, espessura dos horizontes superficiais, teor de carbono no horizonte A (características dos solos) e entre altura média de plantas no estrato vertical 3 e densidade de lenhosas no segundo estrato; a variável ARGILAB explica $57 \%$ da variância dessas características da vegetação, enquanto as variáveis CASCALHO e SILTEAF explicam $46 \%$ e $45 \%$, respectivamente (correlações elevadas ao quadrado).

Quadro 6. Médias e desvios-padrão, correlações e pares canônicos estimados entre os conjuntos das variáveis de solo e vegetação utilizadas na Análise de Correlação Canônica para Jataúba

\begin{tabular}{|c|c|c|c|c|}
\hline \multirow{2}{*}{ Variável } & \multirow{2}{*}{ Média } & \multirow{2}{*}{ Desvio-padrão } & \multicolumn{2}{|c|}{ Pares canônicos } \\
\hline & & & Primeiro & Segundo \\
\hline ALT3 & 2,383667 & 1,771091 & 0,5840 & 0,8118 \\
\hline $\mathrm{DA} 2$ & 18.258 & 14.928 & 0,9994 & $-0,0333$ \\
\hline ARGILAB & 43,916667 & 8,989472 & 0,7522 & 0,0060 \\
\hline PST & 15,291667 & 10,792376 & $-0,5275$ & $-0,0584$ \\
\hline $\mathrm{COT}$ & 8,763333 & 2,903707 & 0,5154 & 0,7484 \\
\hline NT & 1,034167 & 0,327149 & 0,2767 & 0,8146 \\
\hline $\mathrm{ADPE}$ & 2,230833 & 1,215479 & 0,3555 & 0,1306 \\
\hline ESPEA & 20,416667 & 13,207837 & 0,6373 & $-0,3860$ \\
\hline CASCALHO & 38,416667 & 22,964234 & 0,6772 & $-0,1638$ \\
\hline SILTEAF & 48,666667 & 8,315739 & $-0,6706$ & $-0,3566$ \\
\hline CONDHB & 0,516583 & 1,099449 & 0,0540 & 0,4320 \\
\hline $\mathrm{r}$ & & & 0,9998 & 0,991644 \\
\hline Significância & & & 0,0025 & 0,0649 \\
\hline
\end{tabular}


Estes resultados indicam que a presença de plantas mais altas e a maior densidade de arbustos estão associadas a maiores quantidades de cascalho nos horizontes superficiais e maiores conteúdos de argila em subsuperfície, que proporcionam maior disponibilidade de água no perfil. Observa-se, também, aumento dos teores de $\mathrm{CO}$, de acordo com a altura das árvores e da maior densidade de arbustos, provavelmente pelo maior aporte de serrapilheira nas áreas mais densamente vegetadas.

Santos et al. (1992), relacionando as características da vegetação nativa de caatinga com as propriedades de um Planossolo Nátrico em Parnamirim, PE, observaram que a maior densidade e altura de plantas lenhosas estavam associadas à maior disponibilidade de água e esta, por sua vez, apresentou correlação positiva com os percentuais de cascalho no horizonte superficial. A presença de crostas superficiais, a ocorrência de textura argilosa em subsuperfície e maior susceptibilidade à erosão apresentaram relação com a densidade de plantas herbáceas.

\section{CONCLUSÕES}

1. A densidade absoluta de plantas lenhosas de porte baixo apresentou significativa diminuição de acordo com a intensidade de degradação dos solos. As espécies com maiores densidades relativas foram: Neoglaziovia variegata (caroá) e Cordia leucocephala (moleque duro) no ambiente conservado; Bromelia laciniosa (macambira), Aspidosperma pyryfolium (pereiro) e Caesalpinia pyramidalis (catingueira) no ambiente moderadamente degradado; e C. pyramidalis e Sida galheirensis (malva branca) no ambiente degradado.

2. As características dos Planossolos mais bem relacionadas com a vegetação preservada foram os maiores conteúdos de cascalho nos horizontes superficiais, a maior espessura dos horizontes A + E, e os teores mais elevados de $\mathrm{CO}$, enquanto a ocorrência de encrostamento superficial e erosão e os elevados teores de $\mathrm{Na}$ trocável foram relacionados com a vegetação degradada.

\section{AGRADECIMENTOS}

Os autores agradecem a Mona Andrade Nagai, José de Almeida Lima Neto, Jane Kelly Silva Araújo e Sandro Augusto Bezerra, pelo suporte técnico às atividades de campo e laboratório, e a Leonardo Nogueira Maciel e Ladivânia Nascimento, pela coleta e identificação das espécies vegetais.

\section{LITERATURA CITADA}

ACCIOLY, L.J.O. Degradação do solo e desertificação no Nordeste do Brasil. B. Inf. SBCS, 25:1:23-25, 2000.
ALCOFORADO-FILHO, F.G.; SAMPAIO, E.V.S.B. \& RODAL, M.J.N. Florística e fitossociologia de um remanescente de vegetação caducifólia espinhosa arbórea em Caruaru, Pernambuco. Acta Bot. Bras., 17:287-303, 2003.

ANDRADE, L.A.; PEREIRA, I.M.; LEITE, U.T. \& BARBOSA, M.R.V. Análise da cobertura de duas fisionomias de caatinga, com diferentes históricos de uso, no município de São João do Cariri, Estado da Paraíba. R. Cerne, 11:253-262, 2005.

ARAÚJO, E.L.; SAMPAIO, E.V.S.B. \& RODAL, M.J.N. Composição florística e fitossociologia de três áreas de caatinga de Pernambuco. R. Brasil. Biol., 55:595-607, 1995.

ARAÚJO FILHO, J.A. \& CARVALHO, F.C. Desenvolvimento sustentado da caatinga. In: ALVAREZ V., V.H.; FONTES, L.E.F. \& FONTES, M.P.F., eds. O solo nos grandes domínios morfoclimáticos do Brasil e o desenvolvimento sustentado. Viçosa, MG, SBCS/UFV/DPS, 1996. p.125-133.

BRASIL. Ministério do Meio Ambiente dos Recursos Hídricos e da Amazônia Legal - MMA. Desertificação. In: CONFERÊNCIA DAS PARTES DA CONVENÇÃO DAS NAÇÕES UNIDAS DE COMBATE À DESERTIFICAÇÃO, 3., Brasília, 1999. 23p.

BRASIL. Ministério do Meio Ambiente dos Recursos Hídricos e da Amazônia Legal - MMA. Mapa de ocorrência da desertificação e áreas de atenção especial. Brasília, Plano Nacional de Combate à Desertificação, 1998.

CONSELHO NACIONAL DA RESERVA DA BIOSFERA DA CAATINGA - CNRBC. Cenários para o Bioma Caatinga. Recife, Secretaria de Ciência, Tecnologia e Meio Ambiente, 2004. 283p.

EMPRESA BRASILEIRA DE PESQUISA AGROPECUÁRIA EMBRAPA. Centro Nacional de Pesquisa de Solos. Manual de métodos de análise de solos. Rio de Janeiro, 1997. 212p.

EMPRESA BRASILEIRA DE PESQUISA AGROPECUÁRIA EMBRAPA. Centro Nacional de Pesquisa de Solos. Sistema brasileiro de classificação de solos. Rio de Janeiro, 2006. 306p.

FOX, D.M.; BRYAN, R.B. \& PRICE, A.G. The role of soil surface crusting in desertification and strategies to reduce crusting. Environ. Monit. Assessment, 99:149-159, 2004.

GUTIÉRREZ, J.R. \& SQUEO, F.A. Importância de los arbustos em los ecosistemas semiáridos de Chile. Ecosistemas, 2004/1 Disponível em :<URL: http//www.aeet.org/ ecosistemas/041/investigacion2.htm $>$

JACOMINE, P.K.T.; CAVALCANTI, A.C.; BURGOS, N. \& PESSOA, S.C.P. Levantamento exploratório reconhecimento de solos do Estado de Pernambuco. Recife, MA/DNPEA - SUDENE/DRN, 1973. v.1. (Boletim Técnico, 26).

JATOBÁ, L. Geologia e recursos minerais. In: ANDRADE, M.C.O., coord. Atlas escolar pernambucano: espaço geohistórico e cultural. João Pessoa, Grafset, 2003. 160p.

LEMOS, R.C. \& SANTOS, R.D. Manual de descrição e coleta de solo no campo. 3.ed. Campinas, Sociedade Brasileira de Ciência do Solo, 1996. 84p. 
RODAL, M.J.N.; SAMPAIO, E.V.S. \& FIGUEIREDO, M.A. Manual sobre métodos de estudo florístico e fitossociológico: Ecossistema de caatinga. Brasília, Sociedade Botânica do Brasil, 1992. 24p.

RODRIGUES, V. Desertificação: problemas e soluções. In: OLIVEIRA, T.S.; ASSIS JÚNIOR, R.N.; ROMERO, R.E. \& SILVA, J.R.C., eds. Agricultura, sustentabilidade e o semi-árido. Fortaleza, Universidade Federal Ceará, Viçosa, MG, Sociedade Brasileira de Ciência do Solo, 2000. p.137-164.

ROTH, C.H. Soil sealing and crusting in tropical South America. In: SUMNER,M.E. \& STEWART, B.A., eds. Soil crusting: Chemical and physical processes. Boca Raton, Lewis Publishers, 1992. p.267-300.

SAADI, A. Os sertões que viram desertos. B. Inf. SBCS, 25:1:10 $17,2000$.

SAMPAIO, E.V.S.B.; ARAÚJO, E.L.; SALCEDO, I.H. \& TIESSEN, H. Regeneração da vegetação de caatinga após corte e queima, em Serra Talhada, PE. Pesq. Agropec. Bras., 33:621-632, 1998.
SAMPAIO, E.V.S.B. \& SAMPAIO, Y. Desertificação: conceitos, causas, conseqüências e mensuração. Recife, Universidade Federal de Pernambuco, 2002. 85p. (Documento, 1)

SAS Institute. Statistical package. version 8.2. Cary, 1999.

SANTOS, M.F.A.V.; RIBEIRO, M.R. \& SAMPAIO, E.V.S.B. Semelhanças vegetacionais em sete solos da caatinga. Pesquisa Agropecuária Brasileira, 27:305-314 1992.

SNAKIN, V.V.; KRECHETOV, P.P.; KUZOVNIKOVA, T.A.; ALYABINA, I.O.; GUROV, A.F. \& STEPICHEV, A.V. The system of assessment of soil degradation. Soil Technol., 8:331-343, 1996.

SOMBROEK, W. \& SENE, E.H. Land degradation in arid, semi-arid and dry sub-umid areas: Rainfed and irrigated lands, rangelands and woodlands. Disponível em <http:// www.fao.org/documents/show_cdr.asp?url_file=/docrep/ X5308E/X5308E00.htm> Acesso em abr. de 2006.

VASCONCELOS SOBRINHO, J. Processos de desertificação ocorrentes no Nordeste do Brasil: Sua gênese e sua contenção. Recife, SEMA/SUDENE, 1982. 101p. 